\title{
"Trait EI in the relationship between needs fulfilment and symptoms and attitudes associated with EDs"
}

Barberis, N., nbarberis@ unime.it

Università degli Studi di Messina, Dipartimento di Medicina Clinica e Sperimentale Messina, IT

00390906766087

Costa, S., sebastiano.costa@ntu.ac.uk

Nottingham Trent University, Department of Psychology

Nottingham, UK

Cuzzocrea, F., fcuzzocrea@unime.it

Università degli Studi di Messina, Dipartimento di Medicina Clinica e Sperimentale Messina, IT

00390906766087

Quattropani, M.C., mquattropani@unime.it

Università degli Studi di Messina, Dipartimento di Medicina Clinica e Sperimentale

Messina, IT

00390906766087

Corresponding author:

Nadia Barberis

Section of Psychology

University of Messina, Via Bivona, Messina (Italy), 98122.

Tel: +393466483234

Email: nbarberis@unime.it

The authors have no conflict of interest to declare.

Barberis N. assisted with manuscript preparation concept, study design, data analysis and interpretation. Costa $S$ assisted with manuscript preparation, and data interpretation. Cuzzocrea F. assisted with study design and data interpretation. Quattropani MC. assisted with concept and study supervision. All authors take responsibility for the integrity of the data and the accuracy of the data analysis. All authors contributed to and have approved the final manuscript. 
Trait EI, Needs Fulfilment and EDs

Trait EI in the relationship between needs fulfilment and symptoms and attitudes associated with EDs 


\begin{abstract}
Eating disorders (EDs) are a set of pathologies, which have been increasing in prevalence in the recent years, suggesting the importance of studying symptoms and attitudes associated with EDs in depth. Several studies have showed that both psychological basic needs and trait emotion intelligence (trait EI) are relevant aspects of EDs, however these two aspects were never tested concurrently. Previous studies have shown that self-determined motivation could be a plausible antecedent that may account for individual variation in trait EI, and for this reason, it seems to be extremely relevant to integrate trait EI in a Self-Determination Theory (SDT) framework. The aim of this study is to test a mediation model of trait EI in the relationship between need fulfilment and eating disorders. In a sample of 159 females aged between 16 and 22 years old $(\mathrm{M}=18.71 ; \mathrm{SD}=$ 1.98) instruments were administered to measure the basic psychological needs, trait EI, and eating disorders. Results of this study showed that need fulfilment was negatively related to eating disorders and positively related to trait EI, whereas trait EI was negatively related to eating disorders. Furthermore, trait EI has shown a mediation role in the relation between basic psychological needs and eating disorders.
\end{abstract}




\section{Introduction}

\section{Eating Disorders}

Eating disorders (EDs) are a set of pathologies based on harmful relationships with food and weight that can threaten many areas of a person's life, including their health (American Psychiatric Association, 2013; Kazdin, 2000). Types of ED include anorexia nervosa, bulimia nervosa, binge eating disorders, night eating syndrome, pica and rumination (American Psychiatric Association, 2013). The prevalence of EDs is different for each subtype of disorder, varying between 0.4 per cent and 1.6 per cent (American Psychiatric Association, 2013).

Eating disorders are characterized by various eating-related problems such as dietary restriction, binge eating and purging that cause severe distress or apprehension about weight and shape. These behaviours associated with eating disorders can also produce serious organ damage and are often exacerbated by other conditions, such as substance abuse, anxiety disorders or depression. EDs are associated with significant psychosocial impairment, serious medical complications and increased risk of suicide (American Psychiatric Association, 2013), so it is important to know what appear to be the antecedents of symptoms and attitudes associated with EDs to prevent this type of problem.

\section{Antecedents of Eating Disorder}

Previous studies have shown that the prevalence of EDs has been increasing in recent years, suggesting the importance of studying their development in depth (Bulik et al., 2006; Hoek \& Van Hoeken, 2003; Hudson et al., 2007; Preti et al., 2009; Zeiler et al., 2016). Furthermore, EDs have recently received greater public attention in the media than in the past, and there is growing interest in identifying and preventing their onset (Preti et al., 2009). Several studies (Quattropani, Lenzo, \& Filastro, 2017; Sheppes, Suri, \& Gross, 2015; Stanton \& Watson, 2014) have shown how emotional aspects play an increasingly prominent role in the clinical field and in various pathologies, including eating disorders, wherein abundant research has shown that emotions have an extensive influence (e.g. Hambrook, Brown, \& Tchanturia, 2012; Markey \& Vander Wal, 2007; Sassaroli \& 
Ruggiero, 2005), and that psychological factors are implicated in the multifactorial aetiology of eating disorders (Cuzzocrea, Costa, Larcan, \& Toffle, 2015; Quattropani et al., 2016; StriegelMoore \& Bulik, 2007). For instance, maladaptive perfectionism has been shown to be a relevant factor in the prediction of eating disorders (Costa, Hausemblas, Oliva, Cuzzocrea, \& Larcan, 2016; Soenens et al., 2008). Cuzzocrea, Larcan, and Lanzarone (2012) also suggested a relevant role for anxiety in girls, and for neuroticism and psychoticism in boys.

Moreover, Harrison, Sullivan, Tchanturia, and Treasure (2010) emphasized the role of emotional functioning in the development and maintenance of EDs, showing that an ED group reported significantly higher emotional regulation difficulties than a healthy control group. Furthermore, factors such as anxiety, negative mood and interpersonal difficulties seem to be serious risk factors for body dissatisfaction and eating disturbance (Fairburn, Cooper, \& Shafran, 2003). Le Grange et al. (2014) in their study have identified some risk factors for abnormal eating behaviour, such as persistent high weight, mother dieting, low parent attachment, family stress, poor peer relationships and depression. Lavender et al. (2015) have shown in a review that the basis of anorexia and bulimia seems to be a real emotion dysregulation. Nicholls, Devonport, and Blake (2015), in their review, underline that the ED's base, especially binge eating, is a difficulty in managing negative emotions such as stress and depression. Individuals with binge eating tend to use food to avoid negative emotions rather than satiate hunger, so much so that Nicholls et al. (2015) talk about "emotional eating".

\section{Trait Emotional Intelligence and EDs}

Based on the relevant role of emotions, a number of recent studies have begun to examine the association between trait emotional intelligence (trait EI) and eating disorders (Costarelli \& Stamou, 2009; Filaire, Rouveix, \& Larue, 2010; Gardner, Quinton, \& Qualter, 2014; Markey \& Vander Wal, 2007; Swami, Begum, \& Petrides, 2010; Zysberg, 2014; Zysberg \& Rubanov, 2010). Costarelli and Stamou (2009) have shown in fact that women with a high level of disordered eating attitude appear to have a lower level of several facets of trait emotional intelligence, such as 
emotional self-awareness, stress management, empathy, interpersonal relationships and happiness. Similarly, Filaire, Rouveix, and Larue (2010) described that disordered eating attitude was negatively correlated with stress tolerance, emotional self-awareness and general mood. Gardner, Quinton, and Qualter (2014) demonstrated that trait EI predicts bulimic symptoms, binge eating symptoms, and weight and shape concerns. Markey and Vander Wal, (2007) reported, instead, that trait EI contributed to the prediction of bulimic symptomatology, while Zysberg (2014) showed that trait emotional intelligence is negatively correlated with disordered eating. Furthermore, Swami, Begum, and Petrides (2010) reported that trait EI emerged as a significant predictor of actual-ideal weight discrepancy and body appreciation, also after controlling for weight status and media influence, while Zysberg and Rubanov (2010) showed that trait EI is negatively correlated with emotional eating.

Trait EI (or trait emotional self-efficacy) is a set of emotional self-perceptions located at the lower levels of the personality hierarchy (Petrides, Pita, \& Kokkinaki, 2007) and is distinct from ability EI, which is defined as a cognitive ability to understand and manage emotions and should be assessed using tests of maximum performance (Austin, 2009; Ferguson \& Austin, 2010). Trait EI refers to personal perceptions of one's emotional abilities and is defined by fifteen trait emotional intelligence facets (trait optimism, trait happiness, self-esteem, emotion management, assertiveness, social awareness, trait empathy, emotion perception, emotion expression, relationships, emotion regulation, impulse control, stress management, self-motivation and adaptability) that represent the sampling domain. Numerous studies have verified that trait EI is implicated in many important domains, such as medicine (Barberis et al., 2016; Costa, Petrides, \& Tillman, 2014), parenting (Gugliandolo, Costa, Cuzzocrea, \& Larcan, 2015) and university performance (Sanchez-Ruiz, Mavroveli, \& Poullis, 2013), confirming the relevant role of trait EI in positive personal development and well-being (Martins, Ramalho, \& Morin, 2010). Specifically, previous studies have shown that trait EI has a negative association with depression (Dawda \& Hart, 2000), psychopathy (Malterer, Glass, \& Newman, 2008), personality disorders (Petrides et al., 2007) and 
psychosomatic complaints (Andrei \& Petrides, 2013), while positively promoting general health (Greven, Chamorro-Premuzic, Arteche, \& Furnham, 2008), quality of life (Gourzoulidis et al., 2015), physical health and health behaviours (Fernández-Abascal \& Martín-Díaz, 2015).

Although there is a clear consensus about the consequences of trait EI, studies on the antecedents of trait EI are relatively scarce. A very interesting contribution in this field was provided by Perreault, Mask, Morgan, and Blanchard (2014), whose research integrated trait EI into a self-determination theory (SDT) framework, suggesting general self-determined motivation as a plausible antecedent that may account for individual variation in trait EI, resulting in differing levels of psychological well-being.

\section{Self-Determination Theory and EDs}

Self-determination theory is a meta-theory of human motivation, development and health which assumes that humans are naturally active organisms with an inherent propensity to achieve personal growth and development. Central to SDT is the existence of three basic psychological needs (autonomy, competence and relatedness), which are considered the essential nutrients for optimal functioning. Much of the research on SDT's notion of needs fulfilment has found that the satisfaction of these three needs is positively related to well-being in several contexts. For instance, a positive relationship was observed between needs fulfilment and positive outcomes such as vitality, school engagement and self-esteem (Chen et al., 2015; Costa, Gugliandolo, Barberis, \& Larcan, 2016; Sulea et al., 2015); moreover, negative relations were observed with internalizing distress, depression, burn-out and other indicators of ill-being (Chen et al., 2015; Costa et al., 2016 Inguglia, Ingoglia, Liga, Lo Coco, \& Cricchio, 2015; Inguglia et al., 2016; Van den Berghe et al., 2014). These basic psychological needs have also been shown to play a crucial role in the development of eating disorders (Froreich, Vartanian, Zawadzki, Grisham, \& Touyz, 2017; Pelletier, Dion, \& Lévesque, 2004; Thøgersen-Ntoumani \& Ntoumanis, 2007). Bartholomew, Ntoumanis, Ryan, Bosch, and Thøgersen-Ntoumani (2011) have in fact shown a positive relationship between the frustration of basic psychological needs and eating disorder symptoms, 
suggesting that individuals could develop rigid behaviour patterns such as restricted eating behaviours or compulsive compensatory behaviours (e.g. vomiting, purging or excessive exercising) in order to try to gain control over their life through bodily control (need for autonomy and competence) or to attempt to gain social approval by meeting standards of an ideal physique (need for relatedness).

\section{The present study}

The above studies have highlighted that both basic psychological needs and trait EI are relevant aspects of EDs; however, these two aspects have not been tested concurrently. It seems to be extremely relevant to integrate trait EI into a SDT framework. Trait EI is in fact a constellation of emotion-related dispositions and self-perceptions that includes variables that previous studies have pointed to as influenced by needs fulfilment (e.g. happiness, empathy, assertiveness, selfmotivation, self-esteem and stress management). Specifically Pavey, Greitemeyer, and Sparks (2011) suggested that the fulfilment of the need for relatedness could promote empathy, highlighting the bond and identification that people feel with others. Ahmad, Vansteenkiste, and Soenens (2013) have shown that needs fulfilment is positively related to composite scores of adjustment defined by frustration, tolerance, task orientation, assertiveness and peer sociability. Quested et al. (2010) found that dancers with needs fulfilment before a performance had a more positive response to stress. Furthermore, several studies have shown that needs fulfilment predicts happiness, self-esteem and self-motivation (Chen et al., 2015; Demir \& Özdemir, 2010; Ryan \& Deci, 2017), suggesting that needs fulfilment could be a plausible antecedent that may account for individual variation in trait EI (Perreault et al., 2014).

Frustrations in perceived autonomy, competence and relatedness could in fact lead, through the deterioration of emotional management skills, to compensatory processes like unhealthy eating behaviours. Indeed, individuals who experience high levels of needs fulfilment in their lives may also be likely to demonstrate high levels of emotional intelligence because they can decide to express what they feel (autonomy), find skilful ways to control their emotions (competence), show 
affection to those close to them and ask for emotional support (relatedness). In turn, high levels of trait EI could contribute to preventing the development of eating disorders in persons who are 'at risk', through emotional self-awareness and the ability to control emotions and cope with everyday difficulties. For these reasons, the aim of this study is to test a mediation model of trait EI in the relationship between needs fulfilment and eating disorders. Furthermore, despite the evidence that eating disorders are related to both basic psychological needs and trait EI, the roles of both aetiological factors (basic psychological needs and trait EI) have not been investigated concurrently in relation to eating disorders. Another innovative aspect of this study could be to identify the role of trait EI as a mechanism through which risks of EDs that are related to basic psychological needs can be increased or reduced. In summary, the aim of this study is to verify a model (Figure 1) with the following paths:

- Needs fulfilment that predicts trait EI and EDs.

- $\quad$ Trait EI that predicts EDs.

- Trait EI that mediates the relationship between needs fulfilment and EDs.

\section{[INSERT HERE FIGURE 1]}

\section{Method}

\section{Partecipants}

The sample consisted of 159 female subjects aged between 16 and 22 years old $(M=18.71$; $\mathrm{SD}=1.98)$. All participants were Italian, with an average body mass index (BMI) in the normal range $(\mathrm{M}=21.50, \mathrm{SD}=3.21 ; 95 \%$ confidence interval, 21.01-22.05). Regarding educational level, $48 \%$ had completed secondary school, $49 \%$ had a high school diploma, $2 \%$ had a degree, while $1 \%$ had not reported this information. Only $14 \%$ of the subjects followed a diet, and $54 \%$ of the sample engaged in physical activity. Also, 13 subjects, evaluated through the eat-26, met the criteria to be classified as at risk for an eating disorder. 


\section{Measures}

Needs: The Basic Psychological Needs Scale (Chen et al., 2014; Costa et al., 2017) is a selfreport questionnaire used to evaluate the satisfaction and frustration of basic psychological needs. It consists of six subscales, each of which includes four items. Examples of the items, together with their relative subscales, are: "I feel a sense of choice and freedom in the things I undertake" ("Satisfaction of the need for Autonomy"), "I feel pressured to do too many things" ("Frustration of the need for autonomy"), "I feel connected with people who care for me, and for whom I care" ("Satisfaction of the need to relatedness"), "I feel excluded from the group I want to belong to", ("Frustration of the need to relatedness"), "I feel capable at what I do", ("Satisfaction of the need for competence"), "I feel like a failure because of the mistakes I make", ("Frustration of the need for competence"). It is also possible to get a full-scale on the satisfaction and a relative frustration. To obtain a total score for satisfaction we took the average of the three scales relating to satisfaction of needs and the reverse score of three scales related to the frustration of needs. The mode of response is a Likert 5-point scale, ranging from "Disagree" to "Agree". The internal consistency of the Needs in this study is reported in Table 1 . The BPNS was widely used in several studies and has shown good level of reliability and relevant validity, supporting a 6-factor structure in several countries, including Italy, with Cronbach's alphas that ranged from 0.61 to 0.88 (Chen et a., 2014; Costa et al., 2017).

Trait EI: The Trait Emotional Intelligence Questionnaire- Short Form (Petrides, 2009) is a 30-item self-report form to evaluate Trait EI. This questionnaire is a short version of the full form. The items are sampled from the 15 facets of Trait EI sampling domain (two items for facet). It is also possible get a score on four factors of major relevance: well-being (e.g.:“On the whole, I'm pleased with my life"), self-control (e.g.:"I usually find it difficult to regulate my emotions"), emotionality (e.g.: "I'm normally able to 'get into someone's shoes' and 'experience their emotions"”) and sociability (e.g.:"I would describe myself as a good negotiator",), as well asa global 
score. Participants are required to rate, on a 7-point scale, their level of agreement with each item. Higher scores indicate higher trait EI. The internal consistency of the trait EI in this study is reported in Table 1. The Trait Emotional Intelligence Questionnaire-SF was widely used in several studies, showing good level of reliability with Cronbach's alphas that ranged from 0.67 to 0.88 and reporting good level of construct, concurrent and incremental validity in several country (Di Fabio, \& Palazzeschi, 2014; Laborde, Allen, \& Guillén, 2016; Siegling, Vesely, Petrides, \& Saklofske, 2015)

Eating Disorder: The Eating Attitudes Test-26 (Garner, Olmsted, Bohr, \& Garfinkel, 1982) is a self-report questionnaire used to evaluate eating disorders, made up 26 items. It consists of three subscales: dieting (e.g.: "Engage in dieting behaviour"), bulimia and food preoccupation (e.g.: "Have the impulse to vomit after meals") and oral control (e.g.: "Cut my food into small pieces"). A total score greater than or equal to 20 indicates the presence of an eating disorder. The mode of response is a Likert 6-point scale, from "Always" to "Never". The internal consistency of the Eating Disorder in this study is reported in Table 1 . The EAT-26 was widely used in several studies and has shown good level of reliability with Cronbach's alphas that ranged from 0.83 to 0.94 and reporting good level of construct, concurrent and predictive validity in several country (Berland et al., 1986; Garner, Olmsted, Bohr, \& Garfinkel, 1982; Orbitello et al., 2006).

\section{Procedures}

The subjects were recruited from among friends and acquaintances of psychology students. Administration took place in a calm and peaceful environment in the presence of a psychology student, and all subjects signed an informed consent form before taking the test. All were guaranteed the anonymity of their data. The protocol took about 30 minutes to be completed. The data were then analyzed using IBM SPSS and AMOS.

\section{Results}


Means and Standard Deviations of scores on each of the variables are shown in Table I. Correlations were conducted between the Needs fulfilment, Trait EI and Eating Disorders variables. Table 1 shows positive correlations between Needs fulfilment, and Trait EI and negative correlations between Needs fulfilment, and Eating Disorders; Trait EI also correlates negatively with Eating Disorders.

\section{[INSERT HERE TABLE 1]}

We used Structural Equation Modelling (SEM) with latent variables to examine whether Trait EI mediates the relationship between Needs fulfilment, and Eating Disorders. The indicators of Needs fulfilment are the three scales of satisfaction of basic needs (autonomy, competence and relatedness) and the inverted score on the three scales of the frustration of needs. Trait EI and EAT were represented, instead, by three parcels of the TEIQue-SF and EAT-26. Instead of using separate items as indicators or the total score, we created 3 parcels of items (making the mean of a set of items) within a factor for the constructs and used these as indicators of the latent constructs. The use of parcel has been chosen for the small sample of this study, in fact parcelling results in a smaller number of indicators per latent factor reducing the number of parameter estimates and this can improve model convergence and model stability. Furthermore individual parcels are likely to have a stronger relation to the latent factor, are less likely to be influenced by method effects, and are more likely to meet the assumptions of normality. To explore the significance of the indirect effects that emerged (i.e. drop from the total to direct effect) we used the bootstrap-generated bias-corrected confidence interval approach (Preacher \& Hayes, 2004; Shrout \& Bolger, 2002).

\section{[INSERT HERE FIGURE 2]}

The fit indices show the goodness of the model: $\chi^{2}(51)=122.58 ; \mathrm{p}<.001 ; \mathrm{CFI}=.92$; RMSEA $=.09(90 \% \mathrm{CI}=.07-.11)$. Needs are related positively to Trait EI $(\beta=.83)$, and Trait EI is related negatively to EAT ( $\beta=-.35$ ), but the direct effect between Needs and Eating Disorderswas not significant $(\beta=.06)$. However, in this model, the indirect relationships of Needs with Eating Disorders mediated by Trait EI were statistically significant (Table 2). 


\section{[INSERT HERE TABLE 2]}

\section{Conclusion}

The purpose of this study was to test a mediation model in which the relationship between needs fulfilment and eating disorders is mediated by trait EI. The results of this study showed that needs fulfilment was negatively related to eating disorders and positively related to trait EI, whereas trait EI was negatively related to eating disorders. Furthermore, trait EI showed a mediation role in the relationship between needs fulfilment and eating disorders.

As expected, both needs fulfilment and trait EI were negatively associated with eating disorders, because low levels of emotional intelligence involve difficulty in regulating emotions, especially negative ones, predisposing the person to bulimia-type issues (Markey \& Vander Wal, 2007). Our results confirmed a plausible role for both variables in the prevention of symptoms and attitudes associated with EDs (Bartholomew et al., 2011; Costarelli \& Stamou, 2009; Markey \& Vander Wal, 2007; Pelletier et al., 2004; Swami et al., 2010; Thøgersen-Ntoumani \& Ntoumanis, 2007). Frustration of psychological needs would render girls vulnerable to eating disorders because of the pervasive lack of control and/or sense of incompetence and isolation which they experience in life (Soenens et al., 2008). Furthermore, eating disorders may not be a consequence only of needs frustration, but also a result of difficulty in regulating the negative emotions that accompany these perceptions, and girls with low levels of trait EI usually experience difficulties in identifying and expressing emotions, and in distinguishing between emotional states and physical sensations (Swami et al., 2010).

Furthermore, the results could suggest that needs fulfilment is a plausible antecedent of eating disorders, accounting for individual variations in trait EI which result in differing levels of psychological well-being (Perreault et al., 2014). This finding is in line with previous studies that integrate trait EI in a self-determination framework (Perreault et al., 2014), suggesting that greater needs fulfilment is (indirectly, through increased trait EI) associated with fewer eating disorders. The persistent experience of needs frustration diminishes self-control (Vansteenkiste \& Ryan, 2013) 
and does not allow the development of adequate strategies to self-regulate emotion, and this could be translated into maladaptive compensatory behaviours to modulate emotions, such as eating disorders.

Finally, this study provides a relevant contribution to the relationship between trait EI and needs fulfilment. Trait EI is in fact a lower level trait in the personality hierarchy that is malleable in response to life experiences (Roberts, Caspi \& Moffitt, 2003; Roberts \& Mroczek, 2008) and therefore of needs fulfilment, defined as "qualities of experience that are essential to any person's well-being” (Sheldon, Ryan, \& Reis, 1996, p. 1277). Furthermore, trait EI is a constellation of emotion-related dispositions and self-perceptions that includes specific domains that previous studies (Ahmad et al., 2013; Chen et al., 2015; Demir \& Özdemir, 2010; Pavey et al., 2011; Quested et al., 2010; Ryan \& Deci, 2017) have shown to be influenced by needs fulfilment (e.g. happiness, empathy, assertiveness, self-motivation, self-esteem and stress management). Needs fulfilment has been shown to be linked to better personal and socioemotional well-being, both as a trait and as daily fluctuations (Reis et al., 2000; Sheldon et al., 1996).

In the present study, there are some limitations to take into consideration. Firstly, the small number of participants necessitates caution about the generalizability of the results. Future studies should try to integrate SDT and trait EI in a wider sample of participants. Secondly, the use of cross-sectional data does not allow inferences to be made about the causal relationship of the variables examined, and future longitudinal and experimental studies are needed to confirm these results. The exclusive use of self-reports could increase measurement bias; for this reason, future studies should use objective measures and/or multi-rating sources (Gugliandolo, Costa, Cuzzocrea, Larcan, \& Petrides, 2015). Future studies could also try to integrate some cognitive and metacognitive variables that have been shown to be relevant in clinical contexts (Lysaker, Dimaggio, \& Brüne, 2016; Macedo, Marques, \& Pereira, 2014; Quattropani, Lenzo, Mucciardi, \& Toffle, 2015, 2016). Thirdly, in this study we used a convenience sample that involved friends and 
psychology students: this could have created bias in the research. In fact, this sample has specific characteristics that do not necessarily resemble the general population.

Despite these limitations, this study provides significant practical and theoretical insights. First of all, from a practical point of view, the results underline the fact that women with unfulfilled basic psychological needs and low trait EI might be vulnerable to developing disordered eating behaviours. Training programmes for eating disorder prevention and intervention should therefore emphasize the promotion of trait EI and psychological needs fulfilment to increase their effectiveness.

Psychotherapies and psychological training programmes that have shown their efficacy in preventive and clinical contexts (Bauer et al., 2013; Evers \& Cierpka, 2015; Lenzo, Gargano, Mucciardi, Lo Verso, \& Quattropani, 2014) could integrate trait EI and basic needs frameworks in order to provide a more complete view of psychopathologies. Finally, integrating aspects of trait EI theory and SDT should provide a more holistic and comprehensive ecological model for the understanding of psychological mechanisms.

\section{References}

1 Ahmad, I., Vansteenkiste, M., \& Soenens, B. (2013). The relations of Arab Jordanian adolescents' perceived maternal parenting to teacher-rated adjustment and problems: The intervening role of perceived need satisfaction. Developmental Psychology, 49(1), 177.

2 American Psychiatric Association. (2013). Diagnostic and statistical manual of mental disorders (5th ed.). Arlington, VA: American Psychiatric Publishing.

3 Andrei, F., \& Petrides, K. V. (2013). Trait emotional intelligence and somatic complaints with reference to positive and negative mood. Psihologija, 46(1), 5-15. 
4 Austin, E. J. (2009). A reaction time study of responses to trait and ability emotional intelligence test items. Personality and Individual Differences, 46(3), 381-383.

5 Barberis, N., Costa, S., Gitto, L., Larcan, R., Buemi, M., \& Santoro, D. (2016). Role of Emotional Intelligence as a Mediating Factor Between Uncertainty and Anxiety Hospital in Chronic Renal Patients, Illness, Crisis \& Loss.

DOI: https://doi.org/10.1177/1054137316667595

6 Bartholomew, K. J., Ntoumanis, N., Ryan, R. M., Bosch, J. A., \&Thøgersen-Ntoumani, C. (2011). Self-determination theory and diminished functioning: The role of interpersonal control and psychological need thwarting. Personality and Social Psychology Bulletin, 36, 754-767.

7 Bauer, S., Papezova, H., Chereches, R., Caselli, G., McLoughlin, O., Szumska, I., \& Moessner, M. (2013). Advances in the prevention and early intervention of eating disorders: The potential of Internet-delivered approaches. Mental Health \& Prevention, 1(1), 26-32.

8 Berland, N. W., Thompson, J. K., \& Linton, P. H. (1986). Correlation between the EAT- 26 and the EAT- 40, the Eating Disorders Inventory, and the Restrained Eating Inventory. International Journal of Eating Disorders, 5(3), 569-574.

9 Bulik, C. M., Sullivan, P. F., Tozzi, F., Furberg, H., Lichtenstein, P., \& Pedersen, N. L. (2006). Prevalence, heritability, and prospective risk factors for anorexia nervosa. Archives of general psychiatry, 63,305-312.

10 Chen, B., Vansteenkiste, M., Beyers, W., Boone, L., Deci, E. L., Van der Kaap-Deeder, J., \& Ryan, R. M. (2015). Basic psychological need satisfaction, need frustration, and need strength across four cultures. Motivation and Emotion, 39, 216-236.

11 Costa, S., Gugliandolo, M. C., Barberis, N., \& Larcan, R. (2016). The mediational role of psychological basic needs in the relation between conception of god and psychological outcomes. Journal of religion and health, 55, 1-16. 
12 Costa, S., Hausenblas, H. A., Oliva, P., Cuzzocrea, F., \& Larcan, R. (2016). Maladaptive perfectionism as mediator among psychological control, eating disorders, and exercise dependence symptoms in habitual exerciser. Journal of behavioral addictions, 5, 77-89.

13 Costa, S., Ingoglia, S., Inguglia, C., Liga, F., Lo Coco, A., \& Larcan, R. (in press). Psychometric Evaluation of Basic Psychological Need Satisfaction and Frustration Scale (BPNSFS) in Italy. Measurement and Evaluation in Counseling and Development, DOI:10.1080/07481756.2017.1347021

14 Costa, S., Petrides, K. V., \& Tillmann, T. (2014). Trait emotional intelligence and inflammatory diseases. Psychology, health \& medicine, 19, 180-189.

15 Costarelli, V., \& Stamou, D. (2009). Emotional intelligence, body image and disordered eating attitudes in combat sport athletes. Journal of Exercise Science \& Fitness, 7, 104-111.

16 Cuzzocrea, F., Costa, S., Larcan, R., \& Toffle, M. E. (2015). Differences between adolescents exhibiting moderate binging and non-binging eating behaviors. SpringerPlus, 4 , 593-603.

17 Cuzzocrea, F., Larcan, R., \&Lanzarone, C. (2012). Gender differences, personality and eating behaviors in non-clinical adolescents. Eating and Weight Disorders-Studies on Anorexia, Bulimia and Obesity, 17, e282-e289.

18 Dawda, D., \& Hart, S. D. (2000). Assessing emotional intelligence: Reliability and validity of the Bar-On Emotional Quotient Inventory (EQ-i) in university students. Personality and individual differences, 28(4), 797-812.

19 Demir, M., \& Özdemir, M. (2010). Friendship, need satisfaction and happiness. Journal of Happiness Studies, 11(2), 243-259.

20 Di Fabio, A., \& Palazzeschi, L. (2012). Incremental variance of the core self-evaluation construct compared to fluid intelligence and personality traits in aspects of decisionmaking. Personality and Individual Differences, 53(3), 196-201. 
21 Evers, O., \& Cierpka, M. (2015). Pathways in prevention-subgroups in an early preventive intervention program and their engagement with the child welfare service. Mental Health \& Prevention, 3(3), 117-128.

22 Fairburn, C. G., Cooper, Z., \& Shafran, R. (2003). Cognitive behaviour therapy for eating disorders: A "transdiagnostic" theory and treatment. Behaviour research and therapy, 41, 509-528.

23 Ferguson, F. J., \& Austin, E. J. (2010). Associations of trait and ability emotional intelligence with performance on Theory of Mind tasks in an adult sample. Personality and Individual Differences, 49(5), 414-418.

24 Fernández-Abascal, E. G., \& Martín-Díaz, M. D. (2015). Dimensions of emotional intelligence related to physical and mental health and to health behaviors. Frontiers in psychology, 6 .

25 Filaire, E., Larue, J., \& Rouveix, M. (2011). Eating behaviours in relation to emotional intelligence. International Journal of sports medicine, 32(04), 309-315.

26 Froreich, F. V., Vartanian, L. R., Zawadzki, M. J., Grisham, J. R., \& Touyz, S. W. (2017). Psychological need satisfaction, control, and disordered eating. British journal of clinical psychology, 56, 53-68.

27 Garner, D. M., Olmsted, M. P., Bohr, Y., \& Garfinkel, P. E. (1982). The eating attitudes test: psychometric features and clinical correlates. Psychological medicine, 12(4), 871-878.

28 Garner, D. M., Olmsted, M. P., Bohr, Y., \& Garfinkel, P. E. (1982). The eating attitudes test: psychometric features and clinical correlates. Psychological medicine, 12, 871-878.

29 Gourzoulidis, G., Kontodimopoulos, N., Kastanioti, C., Bellali, T., Goumas, K., Voudigaris, D., \& Polyzos, N. (2015). Do Self-Perceptions of Emotional Intelligence Predict HealthRelated Quality of Life? A Case Study in Hospital Managers in Greece. Global journal of health science, 7(1), 210. 
30 Greven, C., Chamorro-Premuzic, T., Arteche, A., \& Furnham, A. (2008). A hierarchical integration of dispositional determinants of general health in students: The Big Five, trait emotional intelligence and humour styles. Personality and Individual differences, 44(7), 1562-1573.

31 Gugliandolo, M. C., Costa, S., Cuzzocrea, F., \& Larcan, R. (2015). Trait emotional intelligence as mediator between psychological control and behaviour problems. Journal of Child and Family Studies, 24, 2290-2300.

32 Gugliandolo, M. C., Costa, S., Cuzzocrea, F., Larcan, R., \& Petrides, K. V. (2015). Trait emotional intelligence and behavioral problems among adolescents: A cross-informant design. Personality and Individual Differences, 74, 16-21.

33 Hambrook, D., Brown, G., \& Tchanturia, K. (2012). Emotional Intelligence in ANorexia Nervosa: is Anxiety a missing piece of the puzzle? Psychiatry Research, 200 (1), 12-19.

34 Harrison, A., Sullivan, S., Tchanturia, K., \& Treasure, J. (2010). Emotional functioning in eating disorders: attentional bias, emotion recognition and emotion regulation. Psychological medicine, 40, 1887-1897.

35 Hoek, H. W., \& Van Hoeken, D. (2003). Review of the prevalence and incidence of eating disorders. International Journal of eating disorders, 34, 383-396.

36 Hudson, J. I., Hiripi, E., Pope, H. G., \& Kessler, R. C. (2007). The prevalence and correlates of eating disorders in the National Comorbidity Survey Replication. Biological psychiatry, $61,348-358$.

37 Inguglia, C., Ingoglia, S., Liga, F., Coco, A. L., \& Cricchio, M. G. L. (2015). Autonomy and relatedness in adolescence and emerging adulthood: Relationships with parental support and psychological distress. Journal of Adult Development, 22, 1-13.

38 Inguglia, C., Ingoglia, S., Liga, F., Coco, A. L., Cricchio, M. G. L., Musso, P., ... \& Lim, H. J. (2016). Parenting Dimensions and Internalizing Difficulties in Italian and US Emerging 
Adults: The Intervening Role of Autonomy and Relatedness. Journal of Child and Family Studies, 25, 419-431.

39 Kazdin, A. E. (2000). Encyclopedia of psychology. Washington, D.C: American Psychological Association.

40 Laborde, S., Dosseville, F., Guillén, F., \& Chávez, E. (2014). Validity of the trait emotional intelligence questionnaire in sports and its links with performance satisfaction. Psychology of Sport and Exercise, 15(5), 481-490.

41 Lavender, J. M., Wonderlich, S. A., Engel, S. G., Gordon, K. H., Kaye, W. H., \& Mitchell, J. E. (2015). Dimensions of Emotion Dysregulation in Anorexia Nervosa and Bulimia Nervosa: A Conceptual Review of the Empirical Literature. Clinical Psychology Review, 40, 111-122.

42 Le Grange, D., O’Connor, M., Hughes, E. K., Macdonald, J., Little, K., Olsson, C. (2014). Developmental antecedents of abnormal eating attitudes and behaviors in adolescence. International Journal of Eating Disorders, 47(7), 813-824.

43 Lenzo, V., Gargano, M.T., Mucciardi, M., Lo Verso, G., Quattropani, M.C. (2014). Clinical Efficacy and Therapeutic Alliance in a Time-Limited Group Therapy for Young Adults. Research in Psychoterapy: Psychopathology, Process and Outcome, 17 (1), 9-20-

44 Lysaker, P., Dimaggio, G., \& Brüne, M. (Eds.). (2014). Social cognition and metacognition in schizophrenia: Psychopathology and treatment approaches. Elsevier.

45 Macedo, A., Marques, M., \& Pereira, A. T. (2014). Perfectionism and psychological distress: A review of the cognitive factors. International Journal of Clinical Neurosciences and Mental Health, 1(6), 1-10.

46 Malterer, M. B., Glass, S. J., \& Newman, J. P. (2008). Psychopathy and trait emotional intelligence. Personality and individual differences, 44(3), 735-745.

47 Markey, M. A., \& Vander Wal, J. S. (2007). The role of emotional intelligence and negative affect in bulimic symptomatology. Comprehensive psychiatry, 48, 458-464. 
48 Martins, A., Ramalho, N., \& Morin, E. (2010). A comprehensive meta-analysis of the relationship between emotional intelligence and health. Personality and individual differences, 49, 554-564.

49 Nicholls, W., Devonport, T.J., \& Blake, M. (2015). The association between emotions and eating behaviour in an obese population with binge eating disorder. Obesity Reviews, 1-13

50 Orbitello, B., Ciano, R., Corsaro, M., Rocco, P.L., Taboga, C., Tonutti, L., Armellini, \& Balestrieri, M. (2006). The Eat-26 as screening instrument for clinical nutrition unit attenders. International Journal of Obesity, 30, 977-981.

51 Pavey, L., Greitemeyer, T., \& Sparks, P. (2011). Highlighting relatedness promotes prosocial motives and behavior. Personality and Social Psychology Bulletin, 37(7), 905917.

52 Pelletier, L. G., Dion, S., \& Lévesque, C. (2004). Can self-determination help protect women against sociocultural influences about body image and reduce their risk of experiencing bulimic symptoms. Journal of Social and Clinical Psychology, 23, 61-88.

53 Perreault, D., Mask, L., Morgan, M., \& Blanchard, C. M. (2014). Internalizing emotions: Self-determination as an antecedent of emotional intelligence. Personality and Individual Differences, 64, 1-6.

54 Petrides, K. V. (2009). Technical manual for the Trait Emotional Intelligence Questionnaires (TEIQue). London: London Psychometric Laboratory.

55 Petrides, K. V., Pita, R., \& Kokkinaki, F. (2007). The location of trait emotional intelligence in personality factor space. British journal of psychology, 98, 273-289.

56 Preacher, K. J., \& Hayes, A. F. (2004). SPSS and SAS procedures for estimating indirect effects in simple mediation models. Behavior research methods, 36, 717-731.

57 Preti, A., de Girolamo, G., Vilagut, G., Alonso, J., de Graaf, R., Bruffaerts, R., ... \& ESEMeD-WMH Investigators. (2009). The epidemiology of eating disorders in six 
European countries: results of the ESEMeD-WMH project. Journal of psychiatric research, $43,1125-1132$.

58 Quattropani, M. C., Lenzo, V., \& Filastro, A. (2017). Predictive factors of anxiety and depression symptoms in patients with breast cancer undergoing chemotherapy. An explorative study based on metacognitions. Journal of Psychopathology, 23, 1-7.

59 Quattropani, M. C., Lenzo, V., Mucciardi, M., \& Toffle, M.E. (2015). Psychometric properties of the Italian version of the Short Form of the Metacognition Questionnaire (MCQ-30). Bollettino di Psicologia Applicata, 62 (269), 29-41.

60 Quattropani, M. C., Lenzo, V., Mucciardi, M., \& Toffle, M.E. (2016). Metacognition as predictor of emotional distress in cancer patients. Life Span and Disability,29 (2), 221-239.

61 Quattropani, M.C., Lenzo, V., Faraone, C., Pistorino, G., Di Bella, I., \& Mucciardi, M. (2016). The role of Metacognition in eating behaviour: an exploratory study. Mediterranean Journal of Clinical Psychology, 4 (3), 1-19.

62 Quested, E., Bosch, J. A., Burns, V. E., Cumming, J., Ntoumanis, N., \& Duda, J. L. (2011). Basic psychological need satisfaction, stress-related appraisals, and dancers' cortisol and anxiety responses. Journal of Sport and Exercise Psychology, 33(6), 828-846.

63 Roberts, B. W., \& Mroczek, D. (2008). Personality trait change in adulthood. Current directions in psychological science, 17(1), 31-35.

64 Roberts, B. W., Caspi, A., \& Moffitt, T. E. (2003). Work experiences and personality development in young adulthood. Journal of personality and social psychology, 84(3), 582.

65 Ryan, R. M., \& Deci, E. L. (2017). Self-determination theory: Basic psychological needs in motivation, development, and wellness. Guilford Publications.

66 Sanchez-Ruiz, M. J., Mavroveli, S., \& Poullis, J. (2013). Trait emotional intelligence and its links to university performance: An examination. Personality and Individual Differences, $54,658-662$. 
67 Sassaroli, S., \& Ruggiero, G. M. (2005). The role of stress in the association between low self- esteem, perfectionism, and worry, and eating disorders. International Journal of Eating Disorders, 37, 135-141.

68 Sheldon, K. M., Ryan, R., \& Reis, H. T. (1996). What makes for a good day? Competence and autonomy in the day and in the person. Personality and social psychology bulletin, 22(12), 1270-1279.

69 Sheppes, G., Suri, G., \& Gross, J. J. (2015). Emotion regulation and psychopathology. Annual Review of Clinical Psychology, 11, 379-405.

70 Shrout, P. E., \& Bolger, N. (2002). Mediation in experimental and non experimental studies: New procedures and recommendations. Psychological methods, 7, 422-445.

71 Siegling, A.B., Vesely, A.K., Petrides, K.V., \& Saklofske, D. (2015). Incremental Validity of the Trait Emotional Intelligence Questionnaire-Short Form. Journal of Personality Assessment, 97 (5), 525-535.

72 Soenens, B., Vansteenkiste, M., Vandereycken, W., Luyten, P., Sierens, E., \& Goossens, L. (2008). Perceived parental psychological control and eating-disordered symptoms: Maladaptive perfectionism as a possible intervening variable. The Journal of nervous and mental disease, 196, 144-152.

73 Stanton, K., \& Watson, D. (2014). Positive and negative affective dysfunction in psychopathology. Social and Personality Psychology Compass, 8 (9), 555-567.

74 Striegel-Moore, R. H., \& Bulik, C. M. (2007). Risk factors for eating disorders. American Psychologist, 62, 181-198.

75 Sulea, C., Van Beek, I., Sarbescu, P., Virga, D., \& Schaufeli, W. B. (2015). Engagement, boredom, and burnout among students: Basic need satisfaction matters more than personality traits. Learning and Individual Differences, 42, 132-138. 
76 Swami, V., Begum, S., \& Petrides, K. V. (2010). Associations between trait emotional intelligence, actual-ideal weight discrepancy, and positive body image. Personality and Individual Differences, 49, 485-489.

77 Thøgersen-Ntoumani, C., \& Ntoumanis, N. (2007). A self-determination theory approach to the study of body image concerns, self-presentation and self-perceptions in a sample of aerobic instructors. Journal of Health Psychology, 12, 301-315.

78 Van den Berghe, L., Soenens, B., Aelterman, N., Cardon, G., Tallir, I. B., \& Haerens, L. (2014). Within-person profiles of teachers' motivation to teach: Associations with need satisfaction at work, need-supportive teaching, and burnout. Psychology of Sport and Exercise, 15(4), 407-417.

79 Zeiler, M., Waldherr, K., Philipp, J., Nitsch, M., Dür, W., Karwautz, A., \& Wagner, G. (2016). Prevalence of Eating Disorder Risk and Associations with Health- related Quality of Life: Results from a Large School- based Population Screening. European Eating Disorders Review, 24, 9-18.

80 Zysberg, L. (2014). Emotional intelligence, personality, and gender as factors in disordered eating patterns. Journal of health psychology, 19(8), 1035-1042.

81 Zysberg, L., \& Rubanov, A. (2010). Emotional intelligence and emotional eating patterns: a new insight into the antecedents of eating disorders?. Journal of nutrition education and behavior, 42(5), 345-348. 
Table 1 -Descriptive Analyses and Correlations

\begin{tabular}{lrrrrrrr}
\hline & $\alpha$ & Min & Max & M & SD & 1 & 2 \\
\hline 1.Needs Fulfilment & .92 & 2.58 & 5 & 4 & .59 & & \\
2.Trait EI & .80 & 2.46 & 6.60 & 4.76 & .73 & $.71^{*}$ & \\
3.Eating Attitudes & .81 & 0 & 36 & 7.6 & 7.78 & $-.23^{*}$ & $-.33^{*}$ \\
\hline
\end{tabular}

Note: * $\mathrm{p}<.01$ 
Table 2 - Path estimates, SEs and 95\% CIs

\begin{tabular}{lcccc}
\hline & $\beta$ & B-SE & Lower bound (BC) & Upperbound (BC) \\
& & & $95 \%$ CI & \\
\hline Direct Effect & .83 & .04 & -.74 & -.91 \\
Needs Fulfilement $\rightarrow$ Trait EI & .06 & .22 & -.27 & .63 \\
Needs Fulfilment $\rightarrow$ Eating Disorders & -.35 & .22 & -.97 & -.06 \\
Trait EI $\rightarrow$ Eating Disorders & & & & -.05 \\
Indirect effect via Trait EI & & & & \\
Needs Fulfilment $\rightarrow$ Eating Disorders & .36 & .20 & -.85 & \\
\hline
\end{tabular}

Note: $\mathrm{B}-\mathrm{SE}=$ bootstrapped standards errors; $\mathrm{BC}$ 95\% CI = Bias Corrected-Confidence Interval. 
Figure 1 - Hypothesized Model

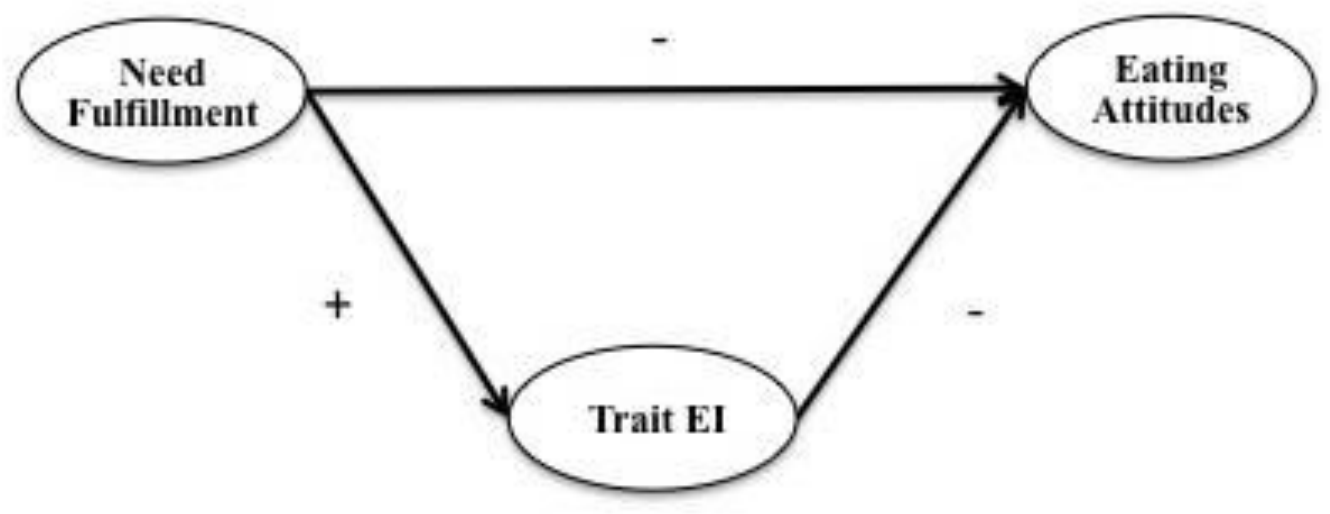

Figure 2 - Structural model of associations between Needs Fulfilment, Trait Ei and Eating Attitudes

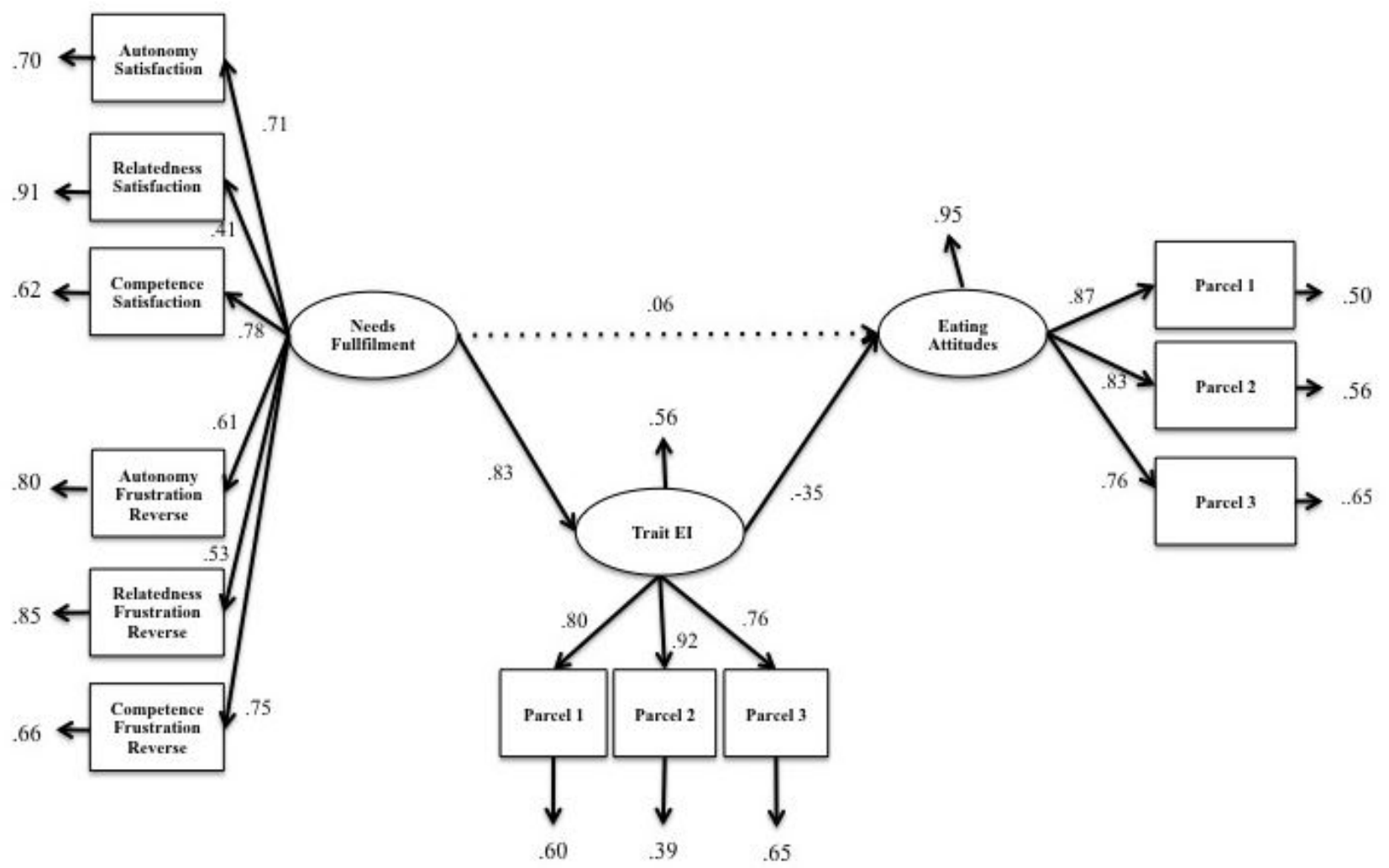

Note: Coefficients shown are standardized path coefficients. Dottted lines represent not significance relations 